\title{
Trauma Surgery $\&$ Acute Care Open \\ Outcomes of major trauma among patients with chronic kidney disease and receiving dialysis in Nova Scotia: a retrospective analysis
}

\author{
Ryan Pratt (D) ,' Mete Erdogan, ${ }^{2}$ Robert Green, ${ }^{3}$ David Clark, ${ }^{1}$ Amanda Vinson, \\ Karthik Tennankore ${ }^{1}$
}

'Nephrology, QEll Health Sciences Centre, Halifax, Nova Scotia, Canada

${ }^{2}$ Trauma Nova Scotia, Nova Scotia Health, Halifax, Nova Scotia, Canada

${ }^{3}$ Emergency Medicine and Critical Care, QEII Health

Sciences Centre, Halifax, Nova Scotia, Canada

Correspondence to Dr Karthik Tennankore; KarthikK. Tennankore@nshealth.ca

Received 5 January 2021 Revised 18 March 2021 Accepted 23 March 2021 (c) Author(s) (or their employer(s)) 2021. Re-use permitted under CC BY-NC. No commercial re-use. See rights and permissions. Published by BMJ.

\section{To cite: Pratt $R$}

Erdogan M, Green R, et al.

Trauma Surg Acute Care Open 2021:6:e000672.
ABSTRACT

Background The risk of death and complications after major trauma in patients with chronic kidney disease (CKD) is higher than in the general population, but whether this association holds true among Canadian trauma patients is unknown.

Objectives To characterize patients with CKD/receiving dialysis within a regional major trauma cohort and compare their outcomes with patients without CKD. Methods All major traumas requiring hospitalization between 2006 and 2017 were identified from a provincial trauma registry in Nova Scotia, Canada. Trauma patients with stage $\geq 3$ CKD (estimated glomerular filtration rate $<60 \mathrm{~mL} / \mathrm{min} / 1.73 \mathrm{~m}^{2}$ ) or receiving dialysis were identified by cross-referencing two regional databases for nephrology clinics and dialysis treatments. The primary outcome was in-hospital mortality; secondary outcomes included hospital/ intensive care unit (ICU) length of stay (LOS) and ventilator-days. Cox regression was used to adjust for the effects of patient characteristics on in-hospital mortality. Results In total, 6237 trauma patients were identified, of whom 4997 lived within the regional nephrology catchment area. CKD/dialysis trauma patients ( $n=101$; 28 on dialysis) were older than patients without CKD ( $n=4896)$, with higher rates of hypertension, diabetes, and cardiovascular disease, and had increased risk of in-hospital mortality (31\% vs $11 \%, \mathrm{p}<0.001)$. No differences were observed in injury severity, ICU LOS, or ventilator-days. After adjustment for age, sex, and injury severity, the HR for in-hospital mortality was 1.90 (95\% Cl 1.33 to 2.70) for CKD/dialysis compared with patients without CKD.

Conclusion Independent of injury severity, patients without CKD/dialysis have significantly increased risk of in-hospital mortality after major trauma.

\section{BACKGROUND}

Trauma patients with underlying chronic kidney disease (CKD) are at higher risk of complications and are more likely to die from these complications compared with patients with other serious medical comorbidities. ${ }^{1-3}$ These risks are even greater in patients with end-stage renal disease (ESRD) despite treatment with renal replacement therapies (RRTs) such as hemodialysis and peritoneal dialysis. ${ }^{12}$ Certain clinical and demographic aspects of patients with CKD have been associated with higher risk of experiencing trauma or suffering complications after traumatic injury. These include hemodynamic and laboratory variables, ${ }^{4-8}$ preceding specialized nephrology care ${ }^{8}$ renal-specific medication use, ${ }^{6}$ frailty, ${ }^{9}{ }^{10}$ RRT modality (peritoneal dialysis vs hemodialysis), ${ }^{511}$ and timing of dialysis treatments. ${ }^{48}$

The best overall index of kidney function is the glomerular filtration rate (GFR), and the National Kidney Foundation recommends using the Chronic Kidney Disease Epidemiology Collaboration (CKDEPI) creatinine equation for estimated glomerular filtration rate (eGFR). ${ }^{12}$ Previous studies investigating characteristics of patients with CKD/ receiving dialysis who experienced major trauma have largely used older methods to classify patients with renal disease ; $^{1-6-11}$ only one used the CKDEPI equation and this study was limited to fallrelated traumas. ${ }^{7}$ Identifying factors associated with adverse outcomes in all trauma patients with CKD and ESRD may lead to optimization of their care.

To date, major trauma outcomes have not been evaluated in a Canadian cohort of patients with CKD. We therefore sought to describe the characteristics of CKD and dialysis patients who experienced major trauma at a Canadian level 1 trauma center. We aimed to compare immediate posttrauma outcomes for patients with $\mathrm{CKD} /$ receiving dialysis versus those without.

\section{METHODS}

\section{Study design and data sources}

We analyzed a cohort of all patients with stage 3-5D CKD,${ }^{13}$ who were followed by the Nova Scotia Central Zone Renal Program and who experienced major trauma requiring admission to the Queen Elizabeth II Health Sciences Centre (QEII HSC) in Halifax, Nova Scotia, Canada between January 1, 2006 and December 31 $1^{\text {st }}$ 2017. The Central Zone Renal Program manages kidney care for approximately $75 \%$ of the population of Nova Scotia (2016 census population 923 598). ${ }^{14}$ Nova Scotia has a provincial trauma service where all major trauma patients are referred for tertiary care to the QEII HSC, the only adult level 1 trauma center in the province. Trauma team leaders include both operation-based and emergency medicine-based specialists.

A waiver of consent was provided by the Nova Scotia Health Research Ethics Board, given this was a retrospective analysis of existing data sources, . The data used have previously been collected as part of the routine care of dialysis/trauma patients. 
No additional information or biological samples were required to be collected as a result of this study and all subsequent analysis and presentations were in aggregate. This study was performed in accordance with the Strengthening the Reporting of Observational Studies in Epidemiology (STROBE) guidelines for reporting observational studies. ${ }^{15}$ It was not appropriate or possible to involve patients or the public in the design, or conduct, or reporting, or dissemination plans of our research.

Three data sources were used to identify patients that were included in the study cohort. Each of these datasets was linked using unique patient identifiers (ie, health card number and date of birth).

1. Trauma patients were identified using the Nova Scotia Trauma Registry (NSTR). The NSTR is a provincial populationbased registry under the Nova Scotia Department of Health and Wellness with data on all patients having an Injury Severity Score (ISS) $\geq 12$ and an appropriate International Classification of Disease External Cause of Injury Code (ICD-10-CA). ${ }^{16}$ The registry also includes penetrating traumas with an ISS $\geq 9$, all trauma team activations regardless of ISS (online supplemental digital content table 1), and traumas resulting in death pre-hospital or in the emergency department (ED). For the purposes of this study, we excluded any trauma patients who resided outside of the Nova Scotia Central Zone catchment area to avoid misclassification bias in coding for $\mathrm{CKD} /$ dialysis (ie, patients outside of this area would not have been captured in either of the two databases noted below).

2. All patients who were followed by the Nova Scotia Central Zone Renal Program and had dialysis initiated between January 1, 2003 and December 31, 2017 were identified using the MyNephrology database. We chose the earliest available date in MyNephrology which was an earlier date range than the NSTR. This ensured that prevalent dialysis patients who experienced trauma would have been included in this study. MyNephrology is a clinical database that contains information on incident in-center hemodialysis patients from dialysis units affiliated with the Nova Scotia Central Zone Renal Program and has been previously used in analyses of patients receiving dialysis from this zone. ${ }^{17}{ }^{18}$ Data collected at the time of dialysis initiation includes information on patient demographics (age, sex), comorbidities and select laboratory values.

3. Patients assessed in the Nova Scotia Central Zone Renal Program outpatient nephrology clinic between January 1, 2003 and December 31, 2017 were identified from the hospital registration system and linked with records from the NSTR to ensure that all patients with CKD who sustained a major trauma during this time period were included. Chart review was performed on those patients identified from the hospital registration system and NSTR as having CKD to verify that only patients with stage 3 or higher CKD (eGFR $<60 \mathrm{~mL} / \mathrm{min} / 1.73 \mathrm{~m}^{2}$ using the CKD-EPI equation) $)^{12}$ at least once in the 6 months prior to the date of hospital admission for trauma were included in the CKD cohort. Patients without dialysis without a measured serum creatinine within 6 months of the admission date for trauma were excluded.

\section{Data collection}

From the NSTR, we collected data on patient demographics (age, sex), cause of injury, injury type (blunt, penetrating, drowning, asphyxia, burns), injury severity (ISS, Glasgow Coma Scale score at the scene and on ED arrival, max Abbreviated
Injury Scale-Head score), number of ventilator days, requirement for and number of blood product transfusions, length of stay (LOS) in the intensive care unit (ICU), in-hospital LOS, National Trauma Registry (NTR) complications, ${ }^{19}$ and in-hospital mortality. Data on in-hospital LOS or mortality occurring outside of a Nova Scotia Health Central Zone facility were not available; these patients are recorded as having transferred to another acute care facility. Data collected from MyNephrology and chart review included laboratory variables (sodium, potassium, calcium, phosphorus, albumin, and urea reduction ratio for dialysis patients at the closest measurement preceding the date of trauma), Charlson Comorbidity Index, and patient comorbidities. Patient name, health card number, and date of birth were used to link records from the NSTR with patients in MyNephrology and with their medical charts. Relevant clinical and demographic data for patients with CKD that were not available from the NSTR or MyNephrology databases were obtained from chart review. Assessment in the ED 30 days prior to the injury date was determined from chart review for patients with CKD and dialysis.

\section{Outcomes}

The primary outcome of this study was in-hospital mortality, defined as death occurring on arrival to the hospital or in any inpatient ward location prior to discharge. Secondary outcomes included in-hospital LOS, ICU LOS, ventilator-days, need for blood transfusion, and number of transfusions (inclusive of blood or other products). In addition, NTR-defined complications arising after trauma were categorized and collected.

\section{Statistical analysis}

Univariable statistics (proportions for categorical variables, mean $\pm S D$ for continuous normally distributed variables and medians/Quartile 1 to Quartile 3 for non-normally distributed variables) were used to describe baseline characteristics of patients with CKD who experienced trauma. Statistical comparisons in available baseline characteristics between those with $\mathrm{CKD} /$ dialysis and without CKD were made using the Wilcoxon rank sum test (for non-normally distributed continuous variables) and $\chi^{2}$ test for categorical variables. A similar approach was used for crude comparisons of outcomes between these two groups.

Unadjusted comparisons of in-hospital outcomes (including mortality, transfusion, ventilator and ICU days/1000 admission days after trauma) were reported using incidence rate ratios with 95\% CIs. The adjusted association of CKD/dialysis status with in-hospital mortality was analyzed using a Cox proportional hazards regression model and reported using a HR with 95\% CI. Proportionality was assessed using Schoenfeld's global test. Only age, sex and injury severity (using ISS) were included in the primary model, as it was determined a priori that comorbidities were likely under-reported in the NSTR cohort. However, we did adjust for select comorbidities using available ICD-10-CA codes in a subsequent model. Anticipating a small number of patients with $\mathrm{CKD} /$ receiving dialysis with major trauma, we elected to treat the exposure of interest as a combined group. However, in a sensitivity analysis, we examined the unadjusted association with mortality compared with patients without nonCKD for CKD stage 3 to 5 and dialysis, separately. In keeping with the privacy policy of the Nova Scotia Department of Health and Wellness, any counts less than 5 are suppressed and are reported as $\mathrm{n}<5$. All statistical analyses were performed using Stata (V.16, College Station, TX). 


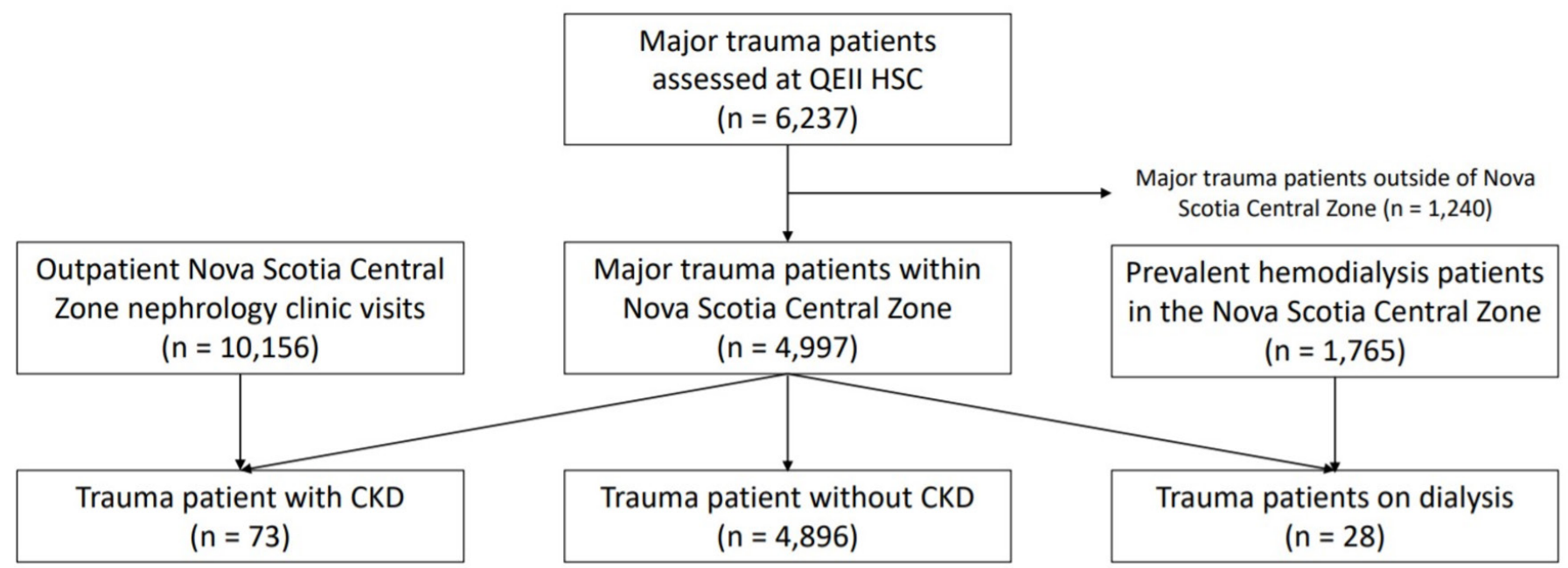

Figure 1 Patient identification and classification into separate cohorts using the inclusion/exclusion criteria described in the text. Trauma records were identified from January 1, 2006 to December 31, 2017. CKD, chronic kidney disease, QEII HSC, Queen Elizabeth II Health Sciences Centre.

Patient and public involvement

No patient involved.

\section{RESULTS}

\section{Patient characteristics}

A total of 6237 patients were assessed for major trauma at the QEII HSC between January 1, 2006 and December 31, 2017 (figure 1). Of these, 4997 patients had postal codes within the Nova Scotia Central Zone. Of these, 73 had stage 3 to 5D CKD, 28 were receiving dialysis, and 4896 were patients without non-CKD/dialysis.

Patient characteristics are shown in table 1 . The $\mathrm{CKD} /$ dialysis cohort was significantly older than the non-CKD cohort and had a greater proportion of female patients. Injury severity was

\begin{tabular}{|c|c|c|c|}
\hline Variable & $\begin{array}{l}\text { No CKD } \\
(n=4896)\end{array}$ & $\begin{array}{l}\text { CKD/dialysis } \\
(n=101)\end{array}$ & $P$ value \\
\hline Age, mean $\pm S D$ & $51 \pm 22$ & $71 \pm 13$ & $<0.001$ \\
\hline Female sex, n (\%) & $1342(27)$ & $41(41)$ & 0.005 \\
\hline ISS, median (Q1-Q3) & $17(13-25)$ & $17(16-25)$ & 0.21 \\
\hline Blunt injury type, n (\%) & $4332(88)$ & $99(98)$ & 0.048 \\
\hline GCS on scene $<8(\mathrm{n}=3937), \mathrm{n}(\%)$ & $429(11)$ & $7(10)$ & 0.85 \\
\hline $\begin{array}{l}\text { Max AIS Head score }>2(n=2684), \\
n(\%)\end{array}$ & $2025(78)$ & $66(93)$ & 0.001 \\
\hline \multicolumn{4}{|l|}{ Comorbidities, ${ }^{*}$ n (\%) } \\
\hline Diabetes & $159(3)$ & $17(17)$ & $<0.001$ \\
\hline Hypertension & $267(5)$ & $20(20)$ & $<0.001$ \\
\hline Congestive heart failure & $39(1)$ & $7(7)$ & $<0.001$ \\
\hline Coronary artery disease & $109(2)$ & $10(10)$ & $<0.001$ \\
\hline Peripheral vascular disease & $27(1)$ & $n<5$ & 0.003 \\
\hline Cerebrovascular disease & $79(2)$ & $n<5$ & 0.08 \\
\hline Chronic lung disease & $70(1)$ & $\mathrm{n}<5$ & 0.18 \\
\hline Dementia & $70(1)$ & $n<5$ & 0.66 \\
\hline
\end{tabular}

${ }^{*}$ Comorbidities were collected from the NSTR using available ICD-10-CA diagnostic codes.

AIS, Abbreviated Injury Score; CKD, chronic kidney disease; GCS, Glasgow Coma Scale; ISS, Injury Severity Score; NSTR, Nova Scotia Trauma Registry; Q1-Q3, Quartile 1-Quartile 3. similar in the $\mathrm{CKD} /$ dialysis and non-CKD groups. There was a significantly higher rate of blunt injury mechanisms in the CKD/ dialysis cohort, with $67 \%$ of injuries in the $\mathrm{CKD} /$ dialysis group occurring as a result of a fall. We also observed a higher rate of serious head injuries in the $\mathrm{CKD} /$ dialysis group.

Additional baseline characteristics of the $\mathrm{CKD} /$ dialysis cohort including comorbidities and pretrauma laboratory values are shown in table 2 . Of the 28 individuals receiving dialysis, the majority (86\%) were receiving in-center hemodialysis. The CKD subcohort had a median preinjury eGFR of $33 \mathrm{~mL} / \mathrm{min} / 1.73 \mathrm{~m}^{2}$.

\section{Primary outcome}

In-hospital mortality was significantly higher in the $\mathrm{CKD} /$ dialysis group (31\% vs $11 \%)$, corresponding to a crude mortality incident rate of 19 deaths per 1000 inpatient-days in the CKD/ dialysis group compared with 7 deaths per 1000 inpatient-days in the non-CKD group (incidence rate ratio 2.60) (table 3). After adjusting for age, sex, and injury severity, patients with $\mathrm{CKD} /$ receiving dialysis had nearly double the risk of mortality compared with the non-CKD group (table 4). The association with mortality persisted after adjustment for ICD-10-CA comorbidities documented in the trauma database. Treating CKD and dialysis as separate exposures, there was a graded effect on mortality that persisted after multivariable adjustment (table 5).

\section{Secondary outcomes}

In unadjusted analysis, there was no significant difference between patients with $\mathrm{CKD} /$ dialysis and without non-CKD in terms of ICU LOS, ventilator-days, or need for any blood product transfusion (table 3). Compared with patients without non-CKD, there were fewer patients with $\mathrm{CKD} /$ receiving dialysis who required any red blood cell transfusion and fewer patients with $\mathrm{CKD} /$ receiving dialysis that returned home after admission for trauma. Occurrence of any in-hospital NTR complication was not significantly different between the CKD/ dialysis and non-CKD groups and only a small proportion $(1 / 101 ; 1 \%$ and $65 / 4891 ; 1 \%$, respectively) experienced three or more complications. Pneumonia was the most common complication for patients with $\mathrm{CKD} /$ receiving dialysis, whereas urinary tract infections were observed most frequently in the non-CKD group. 
Table 2 Characteristics of patients with CKD/receiving dialysis who experienced major trauma

\begin{tabular}{lc}
\hline Variable & $\begin{array}{c}\text { Major trauma patients } \\
(\mathbf{n}=101)\end{array}$ \\
\hline Demographics & $71 \pm 13$ \\
\hline Age, mean \pm SD & $41(41)$ \\
\hline Female sex, $\mathrm{n}(\%)$ & $28(28)$ \\
\hline Receiving dialysis, $\mathrm{n}(\%)$ & \\
\hline Dialysis type, $\mathrm{n}(\%)$ & $73(73)$ \\
\hline None & $24(24)$ \\
\hline In-center hemodialysis & $\mathrm{n}<5$ \\
\hline Home hemodialysis & $\mathrm{n}<5$ \\
\hline Peritoneal dialysis & \\
\hline Dialysis access ( $\mathrm{n}=28), \mathrm{n}$ (\%) & $12(43)$ \\
\hline Arteriovenous fistula & $14(50)$ \\
\hline Hemodialysis catheter & $\mathrm{n}<5$ \\
\hline Peritoneal dialysis catheter & \\
\hline Comorbidities, $\mathrm{n}(\%)$ & $38(38)$ \\
\hline Diabetes & $29(29)$ \\
\hline Congestive heart failure & $35(35)$ \\
\hline Coronary artery disease & $24(24)$ \\
\hline Peripheral vascular disease & $24(24)$ \\
\hline Cerebrovascular disease & $20(20)$ \\
\hline Chronic lung disease & $10(10)$ \\
\hline Malignancy & $6(6)$ \\
\hline Connective tissue disease & $8(8)$ \\
\hline Peptic ulcer disease & $11(11)$ \\
\hline Dementia & $\mathrm{n}<5$ \\
\hline Prior kidney transplant & $6(4-7)$ \\
\hline $\begin{array}{l}\text { Charlson Comorbidity Index score, median score } \\
\text { (Q1-Q3) }\end{array}$ & \\
\hline
\end{tabular}

\begin{tabular}{|c|c|}
\hline $\begin{array}{l}\text { Emergency department visit in } 30 \text { days preceding } \\
\text { trauma, } n(\%)\end{array}$ & $16(16)$ \\
\hline \multicolumn{2}{|l|}{ Injury characteristics } \\
\hline Max AIS Head score $>2$ ( $n=71), n(\%)$ & 66 (93) \\
\hline Max AIS Head score ( $\mathrm{n}=71)$, median (Q1-Q3) & $4(4-5)$ \\
\hline GCS score $(n=73)$, median (Q1-Q3) & $15(13-15)$ \\
\hline GCS score $<8(n=73), n(\%)$ & $7(10)$ \\
\hline ISS, median (Q1--Q3) & $17(16-25)$ \\
\hline Blunt injury type, n (\%) & $99(98)$ \\
\hline \multicolumn{2}{|l|}{ Injury mechanism, n (\%) } \\
\hline Fall & $67(67)$ \\
\hline Motor vehicle collision & $18(18)$ \\
\hline All-terrain or recreational vehicle & $\mathrm{n}<5$ \\
\hline Other* & $12(12)$ \\
\hline \multicolumn{2}{|l|}{ Laboratory values, median (Q1-Q3) } \\
\hline eGFR $(n=73)$ & $33(21-44)$ \\
\hline Albumin $(n=73)$ & $35(31-39)$ \\
\hline Sodium $(n=98)$ & $139(137-141)$ \\
\hline Potassium $(n=100)$ & $4.7[4.3-5.0)$ \\
\hline Calcium $(n=80)$ & $2.25(2.19-2.37)$ \\
\hline Hemoglobin $(n=98)$ & $112(100-128)$ \\
\hline Urea reduction ratio $(n=24)$ & $69(63-76)$ \\
\hline
\end{tabular}

*Assault, animal fall, or not otherwise specified.

AIS, Abbreviated Injury Scale; CKD, chronic kidney disease; eGFR, estimated glomerular filtration rate; GCS, Glasgow Coma Scale; ISS, Injury Severity Score; Q1Q3, Quartile 1-Quartile 3.

\section{DISCUSSION}

In this study, we found that patients with CKD and dialysis have significantly increased risk of mortality after trauma compared with patients without CKD, even after adjustment for age, sex, and injury severity. In keeping with previous findings, the majority of trauma patients were men, although interestingly there was a significantly higher proportion (though still a minority) of women in the $\mathrm{CKD} /$ dialysis group than in the non-CKD group. In some previous studies, women with CKD were more likely to suffer fall-related injuries than men, ${ }^{7}$ but men were more likely to fall than women when patients with ESRD were considered. ${ }^{4} 6$ Patients with $\mathrm{CKD} /$ receiving dialysis also experienced longer hospital LOS and were less likely to be discharged home after suffering a traumatic injury compared with patients without CKD. Unexpectedly, we did not find a higher rate of complications, greater requirement for ICU level of care, or higher blood product transfusion requirements in the $\mathrm{CKD} /$ dialysis group. The significantly lower requirement for any blood products among patients with $\mathrm{CKD} /$ receiving dialysis may be a reflection of the higher mortality in this group (ie, those patients who died did not require blood transfusions). Alternatively, it could be related to more fall-related or blunt injuries in the $\mathrm{CKD} /$ dialysis group, with lower blood product requirements expected. Whereas patients with $\mathrm{CKD} /$ receiving dialysis were more likely to be involved in injuries with a blunt mechanism, injury severity did not significantly differ between patients with $\mathrm{CKD} /$ receiving dialysis and patients without nonCKD. These findings suggest that the presence of CKD or ESRD is an important and independent risk factor for poor outcomes after trauma.

Similar to previous studies, we have shown that patients with renal disease have worse outcomes after trauma. Lorelli et al reported 2.45-fold increased risk of mortality in patients with ESRD compared with the general population after trauma despite similar severities of injury. ${ }^{1}$ Interestingly, Hollis et al observed 22.4-fold increased odds of death in patients with CKD despite lower overall injury severities (ie, ISS $<16$ )..$^{20}$ In a large American cohort study, Bell et al reported 2.34-fold increased HR of failure to rescue (FTR or death subsequent to an adverse event) in patients receiving dialysis after trauma. ${ }^{2}$ More recently, an analysis of geriatric patients with fall-related trauma found that CKD increased 2.5-fold the likelihood of in-hospital mortality. ${ }^{21}$ Whereas we found very similar degrees of overall injury severity between patients with $\mathrm{CKD} /$ receiving dialysis and patients without CKD trauma, our finding of higher rates of head injury among the former group lends support to the idea that patients with $\mathrm{CKD} /$ receiving dialysis experience different types of trauma compared with patients without CKD. Indeed, nearly two-thirds of traumas in the $\mathrm{CKD} /$ dialysis group were due to falls, and this group was also significantly older with a higher comorbidity burden than the non-CKD group. Future research may be needed to analyze if patients with $\mathrm{CKD} /$ receiving dialysis patients who sustain certain types of major trauma (eg, traumatic brain injury) require specialized management strategies.

Our study further adds to the literature on trauma outcomes in patients with pre-existing renal disease by using the CKDEPI equation to identify patients with CKD and describing the components of medical care provided post-trauma including ICU interventions, blood product transfusions, and hospital LOS. We describe dialysis treatments in trauma patients with ESRD in greater detail by examining dialysis vascular access and small-solute dialysis adequacy. These descriptive data thus add to the relatively limited literature on medical care provided to 
Table 3 Crude in-hospital outcomes

\begin{tabular}{|c|c|c|c|c|c|}
\hline Variable & $\begin{array}{l}\text { No CKD } \\
(n=4896)\end{array}$ & $\begin{array}{l}\text { CKD/dialysis } \\
(n=101)\end{array}$ & Incidence rate* & $\begin{array}{l}\text { Unadjusted incidence rate ratio }(95 \% \mathrm{Cl}) \\
\text { comparing } \mathrm{CKD} / \text { dialysis to No CKD }\end{array}$ & $P$ value \\
\hline Any in-hospital complication & $537(11)$ & $16(16)$ & 9/7 & 1.23 (0.70 to 2.02$)$ & 0.40 \\
\hline Need for red cell transfusions & $406(8)$ & $\mathrm{n}<5$ & $1 / 6$ & 0.20 (0.02 to 0.74$)$ & 0.004 \\
\hline Any transfusion & $516(11)$ & $11(10)$ & $6 / 7$ & 0.88 (0.44 to 1.59$)$ & 0.71 \\
\hline Days in hospital & $5(2-15)$ & $7(3-23)$ & - & - & 0.052 \\
\hline Days in ICU & $0(0-3)$ & $0(0-5)$ & $168 / 148$ & 1.14 (0.98 to 1.31$)$ & 0.08 \\
\hline Ventilator days & $0(0-0)$ & $0(0-1)$ & $75 / 75$ & 1.00 (0.84 to 1.19$)$ & 0.96 \\
\hline In-hospital mortality & $525(11)$ & $33(33)$ & $19 / 7$ & 2.60 (1.77 to 3.70$)$ & $<0.001$ \\
\hline Disposition on discharge & & & & & $<0.001$ \\
\hline Home & $3184(65)$ & $48(48)$ & - & - & \\
\hline Other acute care facility & $461(9)$ & $12(12)$ & - & - & \\
\hline Nursing home & $93(2)$ & $\mathrm{n}<5$ & - & - & \\
\hline Rehabilitation facility & $475(10)$ & $\mathrm{n}<5$ & - & - & \\
\hline Other/unknown & $158(3)$ & $n<5$ & - & - & \\
\hline
\end{tabular}

${ }^{*} \mathrm{CKD} /$ dialysis vs no CKD/1000 inpatient-days.

CKD, chronic kidney disease; ICU, intensive care unit.

patients receiving dialysis prior to trauma. Other dialysis-related variables, such as time between hemodialysis sessions, which has been associated with a greater risk of cardiovascular events and mortality, ${ }^{22} 23$ and predialysis blood pressure, ${ }^{6}$ may be important to consider in future studies. The mechanism by which underlying renal disease impacts on trauma patient survival also remains poorly understood. It is possible that the presence of CKD leads to more difficult management of complications (eg, infections, electrolyte/acid-base disturbances, drug toxicity), ${ }^{24}$ with attendant higher mortality. In our experience with patients with CKD who experience major trauma and are seen at the QEII HSC, nephrology services are rapidly requested in the vast majority of cases, thus minimizing any delays to nephrology consultation for these patients.

The strengths of this study include the use of a rigorous patient linkage technique to ensure as many trauma patients with CKD

\begin{tabular}{|c|c|c|c|}
\hline Model & HR & $95 \% \mathrm{Cl}$ & $P$ value \\
\hline \multicolumn{4}{|l|}{ Model 1} \\
\hline CKD/dialysis (vs no CKD) & 2.73 & 1.92 to 3.89 & $<0.001$ \\
\hline \multicolumn{4}{|l|}{ Model 2} \\
\hline CKD/dialysis (vs no CKD) & 1.90 & 1.33 to 2.70 & $<0.001$ \\
\hline ISS (each 1-point increase) & 1.06 & 1.05 to 1.07 & $<0.001$ \\
\hline Age (every year increase) & 1.03 & 1.03 to 1.04 & $<0.001$ \\
\hline Men & 1.04 & 0.87 to 1.25 & 0.67 \\
\hline \multicolumn{4}{|l|}{ Model 3} \\
\hline CKD/dialysis (vs no CKD) & 1.93 & 1.35 to 2.75 & $<0.001$ \\
\hline ISS (each 1-point increase) & 1.06 & 1.05 to 1.07 & $<0.001$ \\
\hline Age (every year increase) & 1.03 & 1.02 to 1.03 & $<0.001$ \\
\hline Men & 1.02 & 0.85 to 1.23 & 0.79 \\
\hline Diabetes & 0.74 & 0.50 to 1.09 & 0.13 \\
\hline Coronary artery disease & 1.50 & 1.06 to 2.12 & 0.021 \\
\hline Cerebrovascular disease & 1.32 & 0.86 to 2.02 & 0.20 \\
\hline Congestive heart failure & 1.61 & 0.99 to 2.60 & 0.06 \\
\hline Peripheral vascular disease & 1.30 & 0.67 to 2.53 & 0.44 \\
\hline
\end{tabular}

CKD, chronic kidney disease; ISS, Injury Severity Score. as possible were included in our analysis and to avoid misclassification and subsequent bias. In addition, the inclusion of manual chart review allowed for a more accurate ability to capture patients with CKD using eGFR, as opposed to simple documentation in the chart or use of an arbitrary creatinine cut-off. In our study, the use of a lower eGFR threshold to define CKD reduced the probability of misclassification due to lack of capture of individuals with earlier stage CKD (in whom nephrology follow-up and regular bloodwork may not have occurred).

Our study also has some important limitations. Unfortunately, data on FTR were not captured in the NSTR, and so it is difficult to distinguish between death due to the original trauma and death due to subsequent complications. Our study was also limited by a lack of complete comorbidity data in the trauma registry as demonstrated by the differences in the proportion of individuals with select comorbid conditions using ICD-10 CA codes from the trauma database versus manual chart review/ database review (not shown). Trauma patients with pre-existing CKD who were not previously seen by a nephrologist may not have been included as they would not have a record in $\mathrm{MyNe}$ phrology; however, we minimized the likelihood of this by using a timeframe for inclusion in MyNephrology of 3 years prior to the first cohort entry in the NSTR. Relatively few patients with other modalities of RRT (eg, peritoneal dialysis and kidney transplant) were identified, which may reflect a lower incidence of

Table 5 Adjusted association between CKD or dialysis status (treated as separate categories) and in-hospital mortality after trauma

\begin{tabular}{llll}
\hline Model & HR & $95 \% \mathrm{Cl}$ & P value \\
\hline Unadjusted & & & \\
$\quad$ No CKD (REFERENCE) & - & - & - \\
CKD & 2.45 & 1.60 to 3.75 & $<0.001$ \\
Dialysis & 3.57 & 1.96 to 6.48 & $<0.001$ \\
Adjusted & & \\
No CKD (REFERENCE) & - & - & - \\
CKD & 1.59 & 1.03 to 2.44 & 0.04 \\
\hline Dialysis & 3.07 & 1.69 to 5.59 & $<0.001$ \\
\hline
\end{tabular}

${ }^{*}$ Adjusted for ISS, age and sex.

CKD, chronic kidney disease; ISS, Injury Severity Score. 
trauma in patients treated with these modalities, as others have suggested. ${ }^{511}$ Finally, although we examined a large and recent trauma cohort, the generalizability of our findings is limited by the small number of patients with $\mathrm{CKD} /$ receiving dialysis who experienced trauma and the fact that this cohort was drawn from a single region in a Canadian province.

In conclusion, patients with $\mathrm{CKD} /$ receiving dialysis are at significantly increased risk of in-hospital mortality after major trauma, independent of injury severity. This risk is higher in patients on dialysis compared with patients with CKD not yet requiring dialysis. We did not find evidence for increased requirements for ICU-level interventions or an increased risk of complications after trauma in patients with $\mathrm{CKD} /$ receiving dialysis compared with patients without CKD. Modified trauma management strategies may be necessary to address the greater mortality risk observed in trauma patients with pre-existing renal disease.

Acknowledgements We wish to acknowledge Susan Arklay-Lehman, Niall Sheehy, and Karen Ssebazza for their assistance in accessing the databases used and performing the cross-referencing between databases. Data used in this research were made available by the Nova Scotia Department of Health and Wellness. Any opinions expressed by the authors do not necessarily reflect the opinion of the Nova Scotia Department of Health and Wellness or Trauma Nova Scotia.

Contributors RP contributed to the literature search, study design, data collection, data analysis, data interpretation, and writing. ME contributed to the literature search, study design, data collection, data analysis, writing, and critical revision. RG contributed to the study design and critical revision. AV and DC contributed to writing and critical revision. KT contributed to the study design, data collection, data analysis, data interpretation, writing, and critical revision.

Funding The authors have not declared a specific grant for this research from any funding agency in the public, commercial or not-for-profit sectors.

Disclaimer Any opinions expressed by the authors do not necessarily reflect the opinion of the Nova Scotia Department of Health and Wellness or Trauma Nova Scotia.

Competing interests None declared.

Patient consent for publication Not required.

Ethics approval Ethical approval was obtained from the Nova Scotia Health Research Ethics Board (ID: 1024623).

Provenance and peer review Not commissioned; externally peer reviewed.

Data availability statement Data are available on reasonable request. Following closure of this study, deidentified study data were stored in a study folder with limited access on the Trauma Nova Scotia shared drive, with access subject to audit. All paper records are stored in a locked filing cabinet within the locked office of $\mathrm{Dr}$ Robert Green (Room 347, Bethune Building, VG Site, QEIl Health Sciences Centre, Halifax, NS). Clinical data used in this study will remain in the MyNephrology and NSTR databases. At the end of a 7-year retention period, all paper documents will be shredded, and destruction of the electronic study files will be performed by Nova Scotia Health IT services.

Open access This is an open access article distributed in accordance with the Creative Commons Attribution Non Commercial (CC BY-NC 4.0) license, which permits others to distribute, remix, adapt, build upon this work non-commercially, and license their derivative works on different terms, provided the original work is properly cited, appropriate credit is given, any changes made indicated, and the use is non-commercial. See: http://creativecommons.org/licenses/by-nc/4.0/.

ORCID iD

Ryan Pratt http://orcid.org/0000-0002-5922-5330

\section{REFERENCES}

1 Lorelli DR, Kralovich KA, Seguin C. The impact of pre-existing end-stage renal disease on survival in acutely injured trauma patients. Am Surg 2001;67:693-6.
2 Bell TM, Zarzaur BL. The impact of preexisting comorbidities on failure to rescue outcomes in nonelderly trauma patients. J Trauma Acute Care Surg 2015;78:312-7.

3 Earl-Royal E, Kaufman EJ, Hsu JY, Wiebe DJ, Reilly PM, Holena DN. Age and preexisting conditions as risk factors for severe adverse events and failure to rescue after injury. I Surg Res 2016;205:368-77

4 Cook WL, Tomlinson G, Donaldson M, Markowitz SN, Naglie G, Sobolev B, Jassal SV. Falls and fall-related injuries in older dialysis patients. Clin J Am Soc Nephrol 2006:1:1197-204.

5 Lin Z-Z, Wang J-J, Chung C-R, Huang P-C, Su B-A, Cheng K-C, Chio C-C, Chien C-C. Epidemiology and mortality of hip fracture among patients on dialysis: Taiwan national cohort study. Bone 2014;64:235-9.

6 Polinder-Bos HA, Emmelot-Vonk MH, Gansevoort RT, Diepenbroek A, Gaillard CAJM. High fall incidence and fracture rate in elderly dialysis patients. Neth J Med 2014;72:509-15.

7 Bowling CB, Bromfield SG, Colantonio LD, Gutiérrez OM, Shimbo D, Reynolds K, Wright NC, Curtis JR, Judd SE, Franch $\mathrm{H}$, et al. Association of reduced eGFR and albuminuria with serious fall injuries among older adults. Clin J Am Soc Nephrol 2016;11:1236-43

8 Plantinga LC, Patzer RE, Franch HA, Bowling CB. Serious fall injuries before and after initiation of hemodialysis among older ESRD patients in the United States: a retrospective cohort study. Am J Kidney Dis 2017;70:76-83.

9 McAdams-DeMarco MA, Suresh S, Law A, Salter ML, Gimenez LF, Jaar BG, Walston JD, Segev DL. Frailty and falls among adult patients undergoing chronic hemodialysis: a prospective cohort study. BMC Nephrol 2013;14:224.

10 Delgado C, Shieh S, Grimes B, Chertow GM, Dalrymple LS, Kaysen GA, Kornak J, Johansen KL. Association of self-reported frailty with falls and fractures among patients new to dialysis. Am J Nephrol 2015;42:134-40.

11 Wang I-K, Cheng Y-K, Lin C-L, Peng C-L, Chou C-Y, Chang C-T, Yen T-H, Huang C-C, Sung F-C, Hsu CY. Comparison of subdural hematoma risk between hemodialysis and peritoneal dialysis patients with ESRD. Clin J Am Soc Nephrol 2015; 10:994-1001.

12 Levey AS, Stevens LA, Schmid CH, Zhang YL, Castro AF, Feldman HI, Kusek JW, Eggers $P$, Van Lente $F$, Greene $T$, et al. A new equation to estimate glomerular filtration rate. Ann Intern Med 2009:150:604-12.

13 Kidney disease: improving global outcomes (KDIGO) CKD work group. KDIGO 2012 clinical practice guideline for the evaluation and management of chronic kidney disease. Kidney Inter Supp/ 2013;3:1-150.

14 Statistics Canada. Nova Scotia [Province] and Canada [Country] (table). Census Profile. 2016 Census. Statistics Canada Catalogue no. 98-316-X2016001. Ottawa. Released November 29, 2017. 2017. https://www12.statcan.gc.ca/censusrecensement/2016/dp-pd/prof/index.cfm?Lang=E (Accessed October 10, 2020).

15 von Elm E, Altman DG, Egger M, Pocock SJ, Gøtzsche PC, Vandenbroucke JP, STROBE Initiative. The strengthening the reporting of observational studies in epidemiology (STROBE) statement: guidelines for reporting observational studies. I Clin Epidemiol 2008:61:344-9.

16 Scotia TN, Report A. 2016. https://www.trauma-ns.com/2016-annual-report (Accessed April 1, 2020)

17 Gomez AT, Kiberd BA, Royston JP, Alfaadhel T, Soroka SD, Hemmelgarn BR, Tennankore KK. Comorbidity burden at dialysis initiation and mortality: a cohort study. Can J Kidney Health Dis 2015;2:68.

18 Alfaadhel TA, Soroka SD, Kiberd BA, Landry D, Moorhouse P, Tennankore KK. Frailty and mortality in dialysis: evaluation of a clinical frailty scale. Clin J Am Soc Nephrol 2015; 10:832-40.

19 Canadian Institute for Health Information. National Trauma Registry Comprehensive Data Set (NTR CDS): Data Element List, as of December. 2001. https://www.cihi.ca/sites/default/files/services_ntr_cdselements_en_0.pdf (Accessed May 1, 2020).

20 Hollis S, Lecky F, Yates DW, Woodford M. The effect of pre-existing medical conditions and age on mortality after injury. J Trauma 2006;61:1255-60.

21 Ahmed N, Greenberg P. Early risk stratification of in hospital mortality following a ground level fall in geriatric patients with normal physiological parameters. Am J Emerg Med 2020;38:2531-5.

22 Foley RN, Gilbertson DT, Murray T, Collins AJ. Long interdialytic interval and mortality among patients receiving hemodialysis. N Eng/ J Med 2011;365:1099-107.

23 Flythe JE, Lacson E. Outcomes after the long interdialytic break: implications for the dialytic prescription. Semin Dial 2012;25:1-8.

24 Bohlouli B, Jackson TJ, Tonelli M, Hemmelgarn B, Klarenbach S. Adverse outcomes associated with preventable complications in hospitalized patients with CKD. Clin J Am Soc Nephrol 2017;12:799-806. 